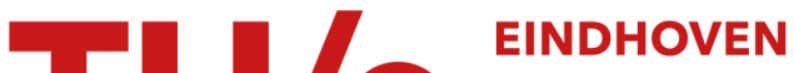 UNIVERSITY OF TECHNOLOGY
}

\section{AWG-based photonic transmitter with DBR mirrors and Mach- Zehnder modulators}

\section{Citation for published version (APA):}

Lawniczuk, K., Kazmierski, C., Wale, M. J., Piramidowicz, R., Szczepanski, P., Smit, M. K., \& Leijtens, X. J. M. (2014). AWG-based photonic transmitter with DBR mirrors and Mach-Zehnder modulators. IEEE Photonics Technology Letters, 26(7), 710-713. https://doi.org/10.1109/LPT.2014.2303496

DOI:

10.1109/LPT.2014.2303496

Document status and date:

Published: 01/01/2014

\section{Document Version:}

Publisher's PDF, also known as Version of Record (includes final page, issue and volume numbers)

\section{Please check the document version of this publication:}

- A submitted manuscript is the version of the article upon submission and before peer-review. There can be important differences between the submitted version and the official published version of record. People interested in the research are advised to contact the author for the final version of the publication, or visit the $\mathrm{DOI}$ to the publisher's website.

- The final author version and the galley proof are versions of the publication after peer review.

- The final published version features the final layout of the paper including the volume, issue and page numbers.

Link to publication

\section{General rights}

Copyright and moral rights for the publications made accessible in the public portal are retained by the authors and/or other copyright owners and it is a condition of accessing publications that users recognise and abide by the legal requirements associated with these rights.

- Users may download and print one copy of any publication from the public portal for the purpose of private study or research.

- You may not further distribute the material or use it for any profit-making activity or commercial gain

- You may freely distribute the URL identifying the publication in the public portal.

If the publication is distributed under the terms of Article 25fa of the Dutch Copyright Act, indicated by the "Taverne" license above, please follow below link for the End User Agreement:

www.tue.nl/taverne

Take down policy

If you believe that this document breaches copyright please contact us at:

openaccess@tue.nl

providing details and we will investigate your claim. 


\title{
AWG-Based Photonic Transmitter With DBR Mirrors and Mach-Zehnder Modulators
}

\author{
Katarzyna Ławniczuk, Christophe Kazmierski, Michael J. Wale, Ryszard Piramidowicz, \\ Paweł Szczepański, Meint K. Smit, and Xaveer J. M. Leijtens
}

\begin{abstract}
In this letter, we demonstrate a novel monolithically integrated photonic multiwavelength transmitter that was realized by integrating an arrayed waveguide grating-based laser with selective distributed Bragg reflector mirrors and Mach-Zehnder modulators. The integrated circuit was designed according to a generic integration model, by utilizing standardized photonic building blocks, and was fabricated on an InP-based platform in a multiproject wafer run. The device delivers above $1 \mathrm{~mW}$ of optical power into the fiber with a side mode suppression ratio better than $40 \mathrm{~dB}$. The linewidth of the generated signals is $275 \mathrm{kHz}$. We achieved error free $50-\mathrm{km}$ transmission at the modulation data rate of $10 \mathrm{~Gb} / \mathrm{s}$ per channel, for a received power of $-26.5 \mathrm{dBm}$.
\end{abstract}

Index Terms-AWG, DBR, generic integration, InP, Mach-Zehnder modulator, multiproject wafer run, multiwavelength transmitter, optical access network, photonic integrated circuit.

\section{INTRODUCTION}

$\mathbf{G}$ ENERIC integration technology has brought a paradigm shift in the field of integrated photonics [1], [2] and changed the way photonic chips are developed, designed, fabricated, packaged and also tested. The fundamental change is based on a design method which freely combines just a few standardized and parameterized photonic building blocks

Manuscript received September 23, 2013; revised December 26, 2013; accepted January 27, 2014. Date of publication January 30, 2014; date of current version March 11, 2014. This work was supported in part by EU FP7/2007-2013 under Grant Agreement 228839: EuroPIC and in part by the European Union in the framework of European Social Fund through the Warsaw University of Technology Development Programme.

K. Ławniczuk is with the Photonic Integration Group, Eindhoven University of Technology, Eindhoven $5600 \mathrm{MB}$, The Netherlands, and also with the Institute of Microelectronics and Optoelectronics, Warsaw University of Technology, Warsaw 00-662, Poland (e-mail: k.lawniczuk@tue.nl).

C. Kazmierski is with the III-V Laboratory, Common Laboratory of AlcatelLucent Bell Labs France, Thales Research and Technology and CEA Leti, Marcoussis 91460, France (e-mail: christophe.kazmierski@3-5lab.fr).

M. J. Wale is with Oclaro Technology Ltd., Towcester NN12 8EQ, U.K., and also with the Photonic Integration Group, Eindhoven University of Technology, Eindhoven 5600 MB, The Netherlands (e-mail: mike.wale@oclaro.com).

R. Piramidowicz is with the Institute of Microelectronics and Optoelectronics, Warsaw University of Technology, Warsaw 00-662, Poland (e-mail: r.piramidowicz@elka.pw.edu.pl).

P. Szczepański is with the Institute of Microelectronics and Optoelectronics, Warsaw University of Technology, Warsaw 00-662, Poland, and also with the National Institute of Telecommunications, Warsaw 04-894, Poland (e-mail: p.szczepanski@elka.pw.edu.pl).

M. K. Smit and X. J. M. Leijtens are with the Photonic Integration Group, Eindhoven University of Technology, Eindhoven 5600 MB, The Netherlands (e-mail: m.k.smit@tue.nl; x.j.m.leijtens@tue.nl).

Color versions of one or more of the figures in this letter are available online at http://ieeexplore.ieee.org.

Digital Object Identifier 10.1109/LPT.2014.2303496
[3] to form complex photonic circuits using sophisticated design tools, powerful component libraries and the highestlevel manufacturing technologies. These approaches together with the fabrication method organized in multi-project wafer (MPW) runs reflect the need for cost-effective solutions that bring photonic devices within the reach of every entity and for multiple applications.

Already a number of such devices were realized on an indium phosphide (InP)-based platform and recently demonstrated [4]-[6]. In this letter we present a novel InP-based, monolithically integrated 8-channel multiwavelength transmitter (MWT) that was fabricated according to this generic model by an industrial foundry partner [7]. The uniformity, reliability of the platform and high yield are provided by the manufacturing partner, which enabled their technology platform used for fabrication of commercial devices such as tunable laserMach-Zehnder PICs employed in tunable XFP-format transceivers. The multiwavelength source implemented within the photonic circuit is based on the operational principle of a linear arrayed waveguide grating-based laser (AWGL) [8]-[10]. These sources use an AWG as intra-cavity filter to determine the generated wavelengths. The lasing wavelength depends on the passband location of each channel of the AWG. The cavity loss is minimal for the specific wavelength corresponding to the particular passband of the AWG, for which the SOA is activated. In the linear configuration of the AWG laser a separate SOA is included for each wavelength, and by biasing more than one SOA at the same time, the source can simultaneously generate several wavelengths. To avoid lasing of the source in the next AWG orders, and thus grating orders different from the central free spectral range (FSR) [11], we implemented into the source wavelength-selective mirrors: DBR gratings. The laser cavity is then formed between the DBR and a cleaved facet (highly reflective: HR coated), as indicated in Fig. 1. This configuration of the multi-channel source allows to freely position the on-chip mirrors, and thus provides flexibility in the resonant cavity length and thus in the longitudinal mode spacing. Recently reported on-chip mirrors, multi-mode interference reflectors [12], provide such flexibility, but are broadband and therefore cannot be used as wavelength selective filters. Lasing in unwanted AWG orders can be avoided with a chirped AWG, but this will complicate the design and increase the intra-cavity loss. By using the wavelength-selective DBR gratings, we suppress lasing in adjacent orders of the AWG. Furthermore, when implementing tunable DBR-based gratings, 


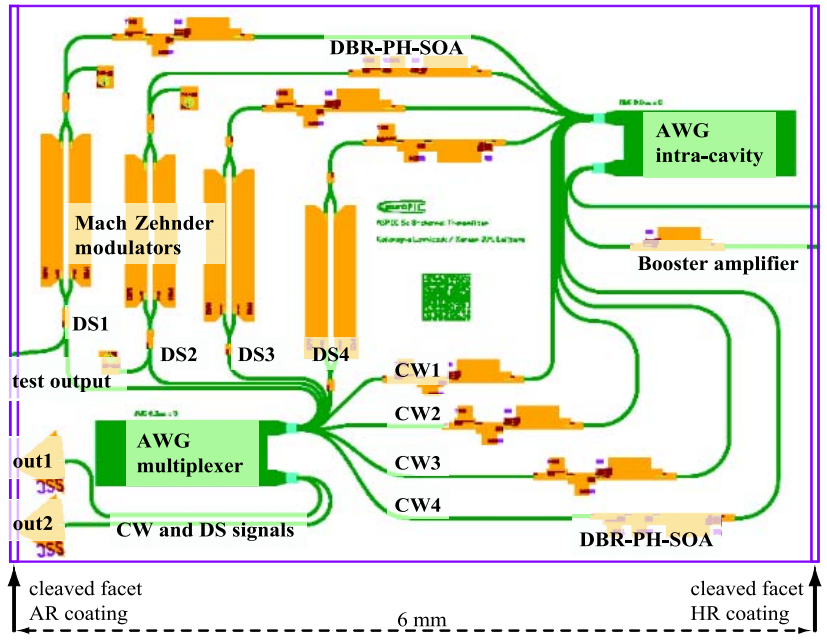

Fig. 1. Mask layout of $4.3 \mathrm{~mm} \times 6 \mathrm{~mm}$ photonic integrated transmitters.

we are able to accurately select the wavelength within the passband of the AWGs, as well as select the operational AWG passband itself. We also obtain a single mode operation without mode hops, and narrow linewidth thanks to the relatively long extended cavity of AWGL. These sources are also easier to drive, as compared to traditional AWGLs, while the tuning precision can be enhanced by introducing phase elements $(\mathrm{PH})$ within the resonant cavity. The proposed configuration of MWT is an alternative design to the MWTs presented in [5] and [13]. The devices reported in [5] and [13] use an array of lasers with an AWG used as multiplexer of optical signals, and external to the cavity.

\section{Device Design}

The MWT chip integrates the following photonic building blocks (BBs): (1) passive waveguide devices; (2) semiconductor optical amplifiers (SOAs), (3) phase modulators and (4) distributed Bragg reflector (DBR) gratings, (5) detectors and (6) spot-size converters; which gives in total $46 \mathrm{BBs}$. The device was designed to operate as a key source localized in the central office (CO) part of the optical access network and simultaneously produce both continuous wave (CW) pilot tones that will act as a carrier for the upstream (UP) data and modulated downstream (DS) data, while the modulation data rate should reach $10 \mathrm{GbE}$ per transmission channel.

The mask layout of the fabricated photonic transmitter is presented in Fig. 1. The device measures $4.3 \mathrm{~mm} \times 6.0 \mathrm{~mm}$ and integrates an AWGL with four electro-optical Mach-Zehnder modulators (MZMs) and a separate AWG used as a multiplexer. The device was designed to simultaneously operate on 8-channels, where four of the generated wavelengths remain $\mathrm{CW}$ signals and four of the generated wavelengths are directed to the MZMs and later used to produce DS data. For our specific application we designed the multiwavelength source with a guard channel, which may be observed in the spectra as an absence of the wavelength peak between generated CW and DS channels. We designed the AWG-based source with the length of the DBR grating section of $150 \mu \mathrm{m}$ giving $40 \%$ of reflection for a grating strength coefficient $\kappa=50 \mathrm{~cm}^{-1}$. The DBR

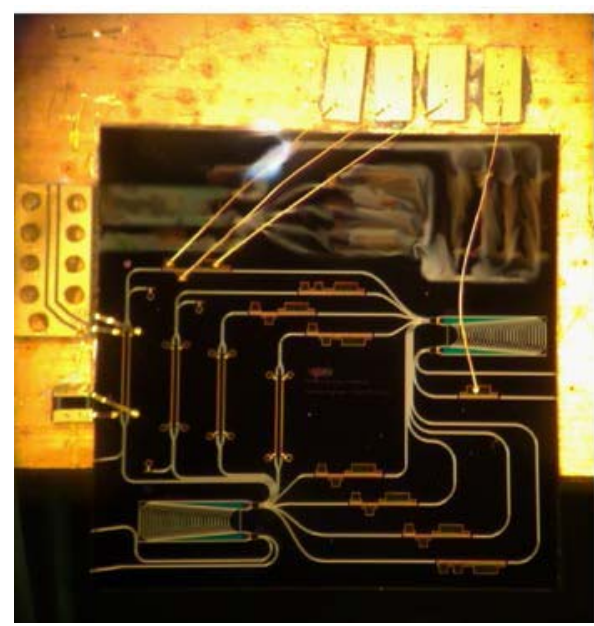

Fig. 2. Mounted and wire-bonded chip on a high RF ceramic submount.

grating can be tuned to a shorter wavelength range by current injection. The mode-hop free operation is achieved by aligning two filters: AWG with the 3-dB passband of $0.5 \mathrm{~nm}$ and DBR grating with the $3-\mathrm{dB}$ passband of $3 \mathrm{~nm}$. We also introduced a $200-\mu \mathrm{m}$-long phase section (PH) within the laser cavity to fine tune the phase of the generated signals. The longitudinal mode spacing is around $0.05 \mathrm{~nm}$. The active sections providing the gain within the structure, namely the SOAs and a booster amplifier, are $500 \mu \mathrm{m}$ long. The MZM intensity lumped modulators are placed outside the laser cavity. The length of the phase modulators used for the MZM implementation is $1000 \mu \mathrm{m}$, which enables more than $10 \mathrm{GHz}$ operation through the quantum confined Stark effect (QCSE). All generated and modulated signals are multiplexed into common optical outputs by a second AWG. The AWGs (the intra-cavity filter and the multiplexer) have identical designs, with a center wavelength $\lambda_{c}=1550 \mathrm{~nm}$, a channel spacing of $100 \mathrm{GHz}(0.8 \mathrm{~nm})$, and with a FSR of $900 \mathrm{GHz}$ $(7.2 \mathrm{~nm})$. The facet of the chip where the optical outputs are positioned, is anti-reflective (AR) coated.

\section{Measurements}

The device was mounted on a high frequency submount. One arm of the Mach-Zehnder modulator was wire bonded on one side to a $50 \Omega \mathrm{RF}$ transmission line and on the other side to a $50 \Omega$ termination for impedance matching. The DC current injection contact pads of the booster, SOA, PH and DBR grating were wire bonded to external DC pads to ease access during characterization. A tilted lensed fiber was used to couple the light out from the chip. The measurements were performed at room temperature, without active cooling of the device. To determine single mode (SM) operation of the AWGL and measure the side-mode suppression ratio (SMSR) we used a high resolution (0.16 pm) Optical Spectrum Analyzer, APEX P2041A. A photograph of the mounted chip is shown in Fig. 2.

During the first experimental stage and tests of the 8-channel transmitter we were able to wire bond only one out of eight channels, thus most of the presented transmission measurement results will refer to channel DS1, using a test 


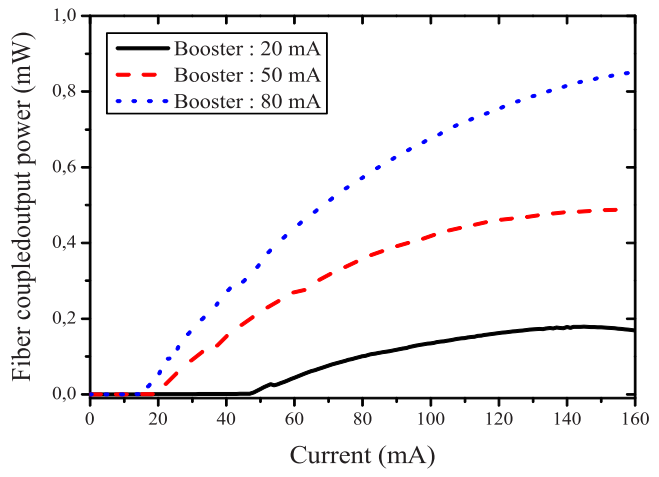

Fig. 3. LI characteristics measured for DS1 channel of AWGL while changing the current injected into the booster amplifier.

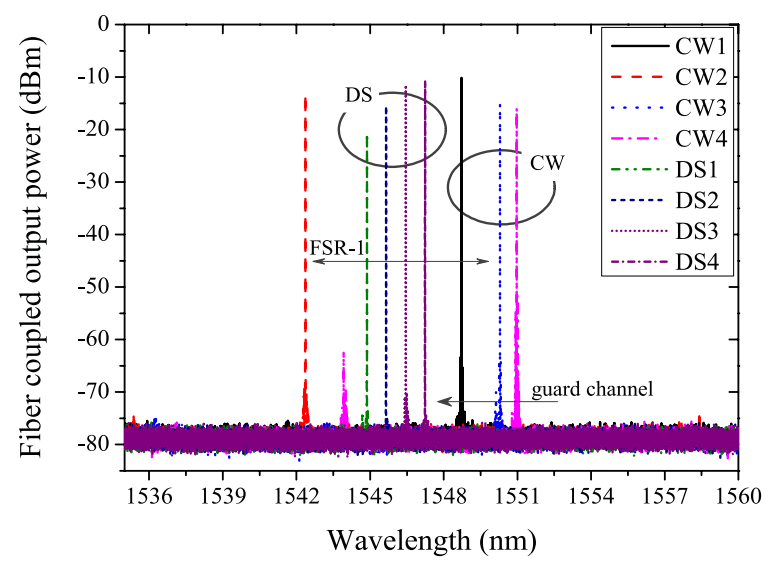

Fig. 4. Spectral characteristics of the MWT while activating each channel consecutively and biasing the booster between $50 \mathrm{~mA}$ and $100 \mathrm{~mA}$.

output, as indicated both in Fig. 1 and in Fig. 2. Nevertheless we expect the performance of all the remained channels to be the same in terms of the modulation data rate.

\section{A. LI and Spectral Characteristics of AWGL}

The measured $L I$ characteristics of AWGL as well as the threshold currents depend on the current injected to the booster amplifier that was placed in the common waveguide within the laser cavity. After activating the booster with $20 \mathrm{~mA}$ and later $50 \mathrm{~mA}$ the detected threshold current decreases from $46 \mathrm{~mA}$ to $20 \mathrm{~mA}$. The measured characteristics of one of the AWGL channels, channel DS1, are presented in Fig. 3. The early thermal roll-off, and thus the power saturation, indicates a relatively high series resistance present at the SOA BB, which induces additional heating of the gain material. The spectra of the MWT detected for every channel biased one by one is presented in Fig. 4. The measurements were performed while biasing the booster between $50 \mathrm{~mA}$ and $100 \mathrm{~mA}$, and activating SOAs between $90 \mathrm{~mA}$ and $160 \mathrm{~mA}$. The generated signals were then multiplexed by AWG to the common output. We obtained SM operation for every channel with a SMSR better than $40 \mathrm{~dB}$. The output power varies per channel, since the SOAs and the booster were not optimized for the power equalization. This will be addressed in our further work, while simultaneously operating all the channels of the transmitter, which will require packaging of the device with multiple DC

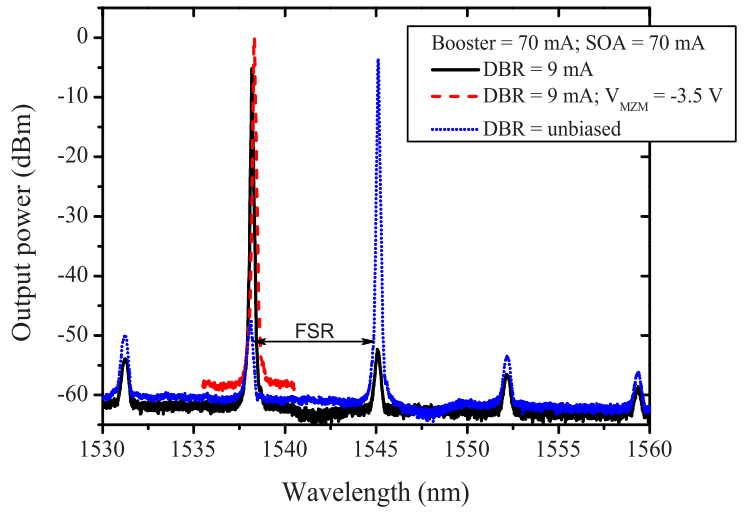

Fig. 5. Detected spectra of DS1 channel while changing bias conditions of DBR grating and Mach-Zehnder modulator.

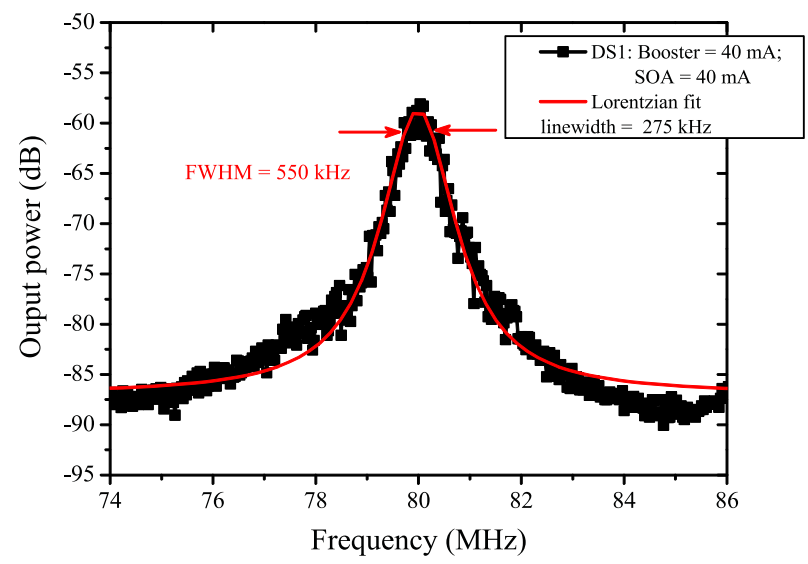

Fig. 6. Measured linewidth of AWG-DBR-laser is $275 \mathrm{kHz}$.

and RF access. The guard channel is visible between the generated DS and CW signals as an absence of the wavelength peak. The passive waveguide loss and bend loss are around $4.5 \mathrm{~dB} / \mathrm{cm}$. The AWG insertion loss is $5 \mathrm{~dB}$. The cavity loss is different for a different channel of the laser (different length of passives) and varies between $6.5 \mathrm{~dB}$ and $8.5 \mathrm{~dB}$.

The implementation of the on-chip selective DBR mirrors results in stable SM operation of the laser in the FSR determined by the gratings bandwidth. The experiment with tuning of the grating section through current injection is presented in Fig. 5. The measured FSR of the AWG is $7.1 \mathrm{~nm}$. The phase section allows to fine-tune our source within the AWG passband in the range of $0.04 \mathrm{~nm}$. The linewidth of the AWG-DBR source is measured with a self-heterodyne setup to be $275 \mathrm{kHz}$. We biased both the booster amplifier and the SOA with $60 \mathrm{~mA}$. The linewidth was found as the full width at half maximum after fitting the RF spectrum with a Lorentzian profile. The measurement result is presented is Fig. 6.

\section{B. Static and Dynamic Performance of MWT}

The measurements of a static extinction ratio (ER) and for obtaining the bit-error-rate (BER) characteristics were performed on channel DS1 of the MWT. The measured $\mathrm{V}_{\pi}$ of a 1-mm-long MZM equals $1.4 \mathrm{~V}$ (reverse bias) with a static ER better than $25 \mathrm{~dB}$. The test results are presented in Fig. 7 . It can be seen that the MZ arms (while not biased) introduce 


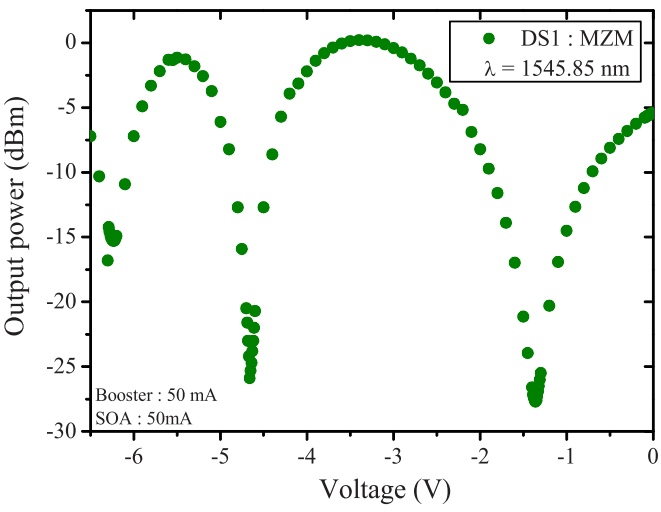

Fig. 7. Static extinction ratio of MZM. The obtained $\mathrm{V} \pi$ is $1.4 \mathrm{~V}$ (reverse biased) with the static ER better than $25 \mathrm{~dB}$.

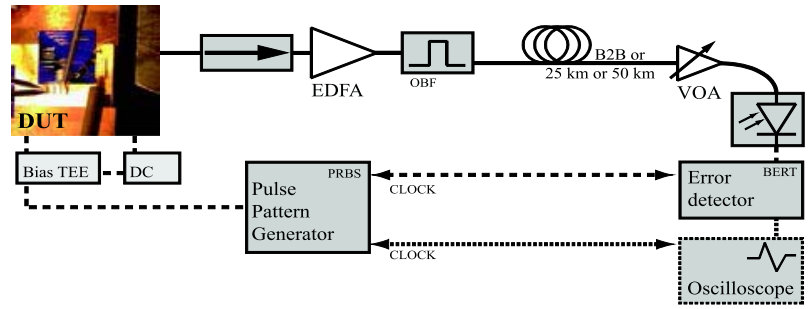

Fig. 8. Schematic of the BER and eye-diagram measurement setups.

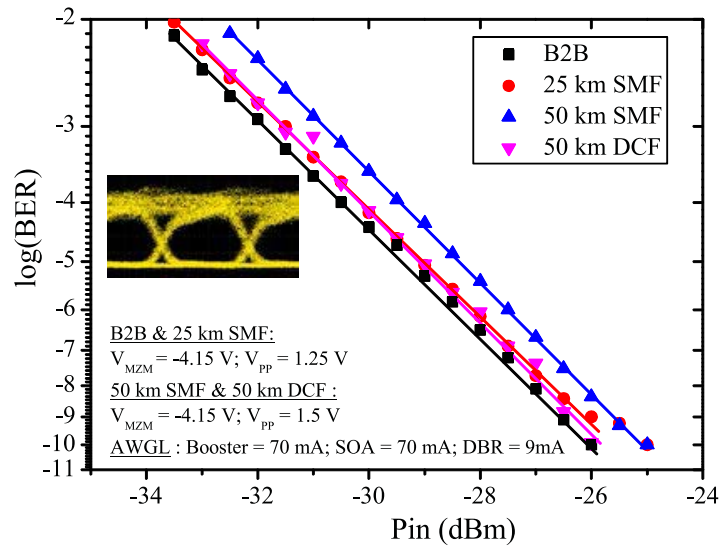

Fig. 9. $10 \mathrm{Gbps}$ BER characteristics detected in B2B configuration and after transmission of the signals in $25 \mathrm{~km}, 50 \mathrm{~km} \mathrm{SMF}$, and $50 \mathrm{~km}$ SMF with DCF.

slightly different phase shift, since we did not obtained the maximum transmission at $0 \mathrm{~V}$ at one of the MMI outputs. The transmission measurements (both BER and eye-diagrams) were performed using setup presented in Fig. 8. The BER characteristics detected in back-to-back (B2B) configuration and after transmitting signals at distances of $25 \mathrm{~km}$ and $50 \mathrm{~km}$ are demonstrated in Fig. 9. We used a PRBS signal of the length of $2^{7}-1$ and $2^{31}-1$, and no difference of the performance of the device was observed. We applied bias voltage of $\mathrm{V}_{\text {MZM }}=-4.15 \mathrm{~V}$, with optimized for transmission $\mathrm{V}_{\mathrm{PP}}$ of $1.25 \mathrm{~V}$ and $1.5 \mathrm{~V}$. The BER measurements were performed at $10 \mathrm{Gbps}$ and reveal error-free operation of the MWT for the received power of $-26.5 \mathrm{dBm}$ with a penalty of only $0.25 \mathrm{~dB}$ after introducing $50 \mathrm{~km}$ long SMF with dispersion compensating fiber (DCF).

\section{CONCLUSION}

We demonstrated operation of a novel monolithically integrated 8-channel photonic multiwavelength transmitter that utilizes an AWG-based laser with wavelength-selective DBR mirrors and electro-optical Mach-Zehnder modulators. The characterization shows very good performance of the photonic circuit, offering error-free transmission at $10 \mathrm{Gbps}$ per channel at a distance of $50 \mathrm{~km}$ (at $\mathrm{P}_{\text {in }}$ of $-26.5 \mathrm{dBm}$ ) with an optical output power up to $1 \mathrm{~mW}$ in fiber, and narrow optical linewidth of $275 \mathrm{kHz}$. The device produces both $\mathrm{CW}$ signals and DS data, which makes it attractive for utilization in optical access networks. The reported transmitter demonstrates the capabilities of a generic integration processes for developing high-performance devices in low-cost MPW-runs.

\section{ACKNOWLEDGMENT}

The authors would like to acknowledge A. Bakker and S. Kriswandhi from PhoeniX Software for their technical support during the design of the mask layout of the transmitter. We would like to thank Nicola Calabretta, Patty Stabile and Rui Lemos Alvares Dos Santos from Eindhoven University of Technology, the Netherlands, for their help during the measurements.

\section{REFERENCES}

[1] M. Smit, et al., "Generic foundry model for InP-based photonics," IET Optoelectron., vol. 5, no. 5, pp. 187-194, Oct. 2011.

[2] F. M. Soares, K. Janiak, J. Kreissl, M. Moehrle, and N. Grote, "Semi-insulating substrate based generic InP photonic integration platform," Proc. SPIE, vol. 8767, pp. 87670M-1-87670M-7, May 2013.

[3] X. J. M. Leijtens, "JePPIX: The platform for InP-based photonics," IET Optoelectron., vol. 5, no. 5, pp. 202-206, 2011.

[4] S. Stopinski, M. Malinowski, R. Piramidowicz, M. Smit, and X. Leijtens, "Monolithically integrated 8-channel WDM reflective modulator," in Proc. OFC/NFOEC, Anaheim, CA, USA, Mar. 2013, pp. 1-3.

[5] K. Lawniczuk, et al., "InP-based photonic multiwavelength transmitter with DBR laser array," IEEE Photon. Technol. Lett., vol. 25, no. 4, pp. 352-354, Feb. 15, 2013.

[6] K. Wang, A. Wonfor, R. V. Penty, and I. White, "Demonstration of cascaded operation of active-passive integrated $4 \times 4$ SOA switches with on-chip monitoring for power control and energy consumption optimization," in Proc. OFC/NFOEC, Anaheim, CA, USA, Mar. 2013, pp. 1-3.

[7] Oclaro, Inc., Caswell, Towcester [Online]. Available: http:// www.oclaro.com

[8] M. Zirngibl and C. Joyner, "12 frequency WDM laser based on a transmissive waveguide grating router," Electron. Lett., vol. 30, no. 9, pp. 701-702, Apr. 1994.

[9] D. Van Thourhout, et al., "High power digitally tunable laser with integrated star coupler," Electron. Lett., vol. 39, no. 4, pp. 370-371, Feb. 2003.

[10] K. Lawniczuk, et al., "8-channel AWG-based multiwavelength laser fabricated in a multi-project wafer run," in Proc. 23rd IPRM, May 2011, pp. $1-4$.

[11] C. R. Doerr. M. Zimgibl, and C. H. Joyner, "Chirping of the waveguide grating router for free spectral range mode selection in the multifrequency laser," IEEE Photon. Technol. Lett., vol. 8, no. 4, pp. 500-502, Apr. 1996.

[12] J. Zhao, E. Kleijn, P. J. Williams, M. K. Smit, and X. J. M. Leijtens, "On-chip laser with multimode interference reflectors realized in a generic integration platform," in Proc. 23rd CSW/IPRM Conf., May 2011, pp. 1-4.

[13] R. Nagarajan, et al., "Single-chip 40-channel InP transmitter photonic integrated circuit capable of aggregate data rate of $1.6 \mathrm{Tbit} / \mathrm{s}, "$ Electron. Lett., vol. 42, no. 13, pp. 771-773, Jun. 2006. 